\title{
Naloxone-Induced Pituitary-Adrenal Activation Does Not Differ in Patients with Depression, Obsessive Compulsive Disorder, and Healthy Controls
}

David Michelson, M.D., Margaret Altemus, M.D., Elise Galliven, B.S., Lauren Hill, B.S., Benjamin D. Greenberg, M.D., Ph.D., and Philip Gold, M.D.

Adrenocorticotropic hormone (ACTH) and cortisol secretion have been shown to be abnormal in approximately half of depressed patients. Information from pituitary and adrenal studies suggests that the locus of this dysregulation is at or above the level of the hypothalamus; however, direct evidence from provocative studies of the hypothalamic corticotropin releasing hormone (CRH) neuron does not exist. The current study was designed to stimulate hypothalamic $C R H$ release using the opiate antagonist naloxone in patients with depression and elevated urinaryfree cortisols as well as healthy and psychiatric controls. All

KEY WORDS: Cortisol; ACTH; Naloxone; Depression; Obsessive-compulsive disorder; Pathophysiology

Major depression is associated with increased adrenal secretion of cortisol and a loss of normal glucocorticoid negative feedback control over hypothalamic-pituitaryadrenal (HPA) axis activity. These phenomena are thought to reflect increased secretion of corticotropin releasing hormone (CRH) from the hypothalamus rather than pituitary or adrenal dysfunction. The evidence for this, however, rests primarily on studies of pituitary-adrenal responses to exogenously administered CRH (Gold et al.

From the Clinical Neuroendocrinology Branch, (DM, EG, LH, PG); and the Laboratory of Clinical Science (MA, BDG), National Institute of Mental Health, Bethesda, Maryland.

Address correspondence to: David Michelson, M.D., CNE/NIMH 10/3S231 MSC 1284, 10 Center Drive, Bethesda, MD 20892-1284,.

Received June 21，1995; revised September 29, 1995; accepted October 3, 1995. subjects received naloxone and placebo on separate days in a double-blinded, randomized fashion at a dose determined previously to reliably induce significant increases in ACTH and cortisol secretion. No significant differences were noted among groups. We conclude that although naloxone is an effective central stimulant of the hypothalamic $C R H$ neuron, stimulation of the hypothalamic $\mathrm{CRH}$ neuron with naloxone does not provide evidence of dysregulation of the HPA axis in depression. [Neuropsychopharmacology 15:207-212, 1996]

1986), which assesses the functional integrity of the pituitary corticotroph cells, and on the measurement of $\mathrm{CRH}$ in the cerebrospinal fluid (CSF) (Nemeroff et al. 1984), which estimates CRH derived from both hypothalamic and extrahypothalmic sources.

Endogenous opiates tonically inhibit hypothalamic $\mathrm{CRH}$ release without influencing either pituitary adrenocorticotropic hormone (ACTH) or adrenocortical cortisol secretion directly (Rittmaster et al. 1985). Opiate receptor blockade using the opiate antagonist naloxone induces pituitary-adrenal activity (Volavka et al. 1979; Morley et al. 1980), an effect most likely mediated by increased hypothalamic CRH secretion (Nikolarakis et al. 1987). The plasma ACTH and cortisol responses to naloxone, thus, can potentially provide a more direct estimate of the activity of hypothalamic CRH secreting neurons than has previously been available.

Although there is a report of a controlled study of naloxone administration to patients with affective dis- 
orders showing no difference in cortisol response between controls and patients (Judd et al. 1981), the effect on ACTH secretion was not examined, and the majority of patients suffered from bipolar illness in a manic state rather than unipolar major depressive illness. We report here a study designed to examine the activity of hypothalamic CRH secreting cells in patients with major depression, obsessive compulsive disorder (OCD), and healthy controls using the opiate antagonist naloxone. Patients with OCD form an interesting group, because they have been shown to have increased CSF CRH levels but not increased HPA axis activity (Altemus et al. 1992). We hypothesized that patients with major depression but not OCD would have an exaggerated pituitary-adrenal response to naloxone administration compared to healthy controls.

\section{METHODS}

\section{Subjects}

Fifteen patients with major depression (11 female, four male, $38.4 \pm 2.2$ years), 15 patients with obsessive compulsive disorder (six female, nine male, $34.4 \pm 2.2$ years), and 22 controls ( 13 female, nine male, $35.5 \pm 2.0$ years) were enrolled. Normal volunteers were recruited through the National Institutes of Health $(\mathrm{NIH})$ normal volunteer office; patients with depression and OCD were recruited directly and through referrals from clinicians in the community. All subjects were medicationfree for at least 2 weeks prior to the study (4 weeks if previously treated with fluoxetine), and all received a complete medical history and screening laboratories including urine drug screens to rule out medical illness or drug abuse. All subjects also received a structured diagnostic interview using the Structured Clinical Interview for DSM-IIIR (SCID). In addition to meeting DSM-IIIR criteria for major depression, depressed patients were evaluated using the Hamilton Depression Rating Scale (21-item) and had scores of at least 16, and patients with OCD, in addition to meeting DSM-IIIR criteria for OCD, had National Institute of Mental Health (NIMH) global OCD scale ratings of 7 or more. To assess baseline HPA axis function, depressed and healthy control subjects collected complete 24-hour urine collections for urinary-free cortisol (UFC) determination (UFC's were not obtained from patients with OCD). The study was approved by the NIMH Institutional Review Board, and all subjects gave informed consent to participate.

\section{Procedures}

Naloxone Administration. On different days separated by at least 48 hours, subjects received placebo or naloxone $(175 \mu \mathrm{g} / \mathrm{kg}$, chosen on the basis of a pilot study with 10 healthy volunteers to determine the low- est maximal stimulatory dose) in a randomized, double-blind fashion. An intravenous catheter was placed at 5:00 P.M., and plasma sampling at 15-minute intervals began at 6:00 P.M. At 7:00 P.M., subjects received naloxone or placebo, and sampling continued every 15 minutes until 9:00 P.M. Naloxone was supplied by the $\mathrm{NIH}$ pharmacy in $25 \mathrm{cc}$ of $0.9 \%$ saline solution and administered as an intravenous bolus over 2 to 3 minutes by nurses blind to condition.

24-Hour Urinary-Free Cortisol. Multiple two or three complete 24-hour urine collections were obtained from 15 depressed patients and 20 healthy controls over a 2-week period. Total creatinine excretion was quantitated to assess completeness of each collection.

Cortisol and ACTH Sample Collection. Samples were collected at 15-minute intervals in ethylenediaminetetra-acetate and immediately chilled on ice. Samples were spun at $4^{\circ} \mathrm{C}$ within 2 hours of collection, frozen over dry ice, and stored at $-70^{\circ} \mathrm{C}$ until assayed.

\section{Assays}

Assays for cortisol were done on previously frozen plasma by commercially available radioimmunoassay (RIA) kits (Diagnostic Products Corporation) [intrassay coefficient of variation (CV) $4.0 \%$; interassay CV 9.4\%]. Assays for ACTH were done on previously frozen plasma by commercially available immunoradiometric assay kits (Nichols) (intrassay CV 5.0\%; interassay CV $6.0 \%$ ). Urinary-free cortisol was measured by a specific RIA after extraction with dichloromethane (Smith Kline Bioscience).

\section{Statistical Analysis}

Baseline ACTH and cortisol levels and net integrated $\mathrm{ACTH}$ and cortisol responses to naloxone were compared among groups using a two-way analysis of variance.

\section{RESULTS}

All values are expressed as mean \pm SEM.

\section{Behavioral Measures}

All subjects in the depressed group met DSM-IIIR criteria for current major depression as assessed by SCID. One subject also met diagnostic criteria for panic disorder, whereas one other subject met diagnostic criteria for generalized anxiety disorder. The mean Hamilton depression rating score among depressed patients was $19.5 \pm 1.1$. All subjects included in the OCD group met DSM-IIIR criteria for OCD as assessed by the SCID. Four subjects with OCD had a concurrent diagnosis of 
major depression, two had a concurrent diagnosis of dysthymia, one had a concurrent diagnosis of bulimia, and two had a concurrent diagnosis of social phobia. The mean Yale-Brown Obsessive Compulsive Scale score for the OCD patients was $24.1 \pm 1.5$. The mean Hamilton depression rating was $11.6 \pm 1.5$ among all OCD patients, $8.5 \pm 1.7$ among non-depressed OCD patients, and $19.5 \pm 1.3$ among OCD patients with concurrent major depression. No healthy volunteer met DSMIIIR criteria for a psychiatric illness.

\section{Baseline Measures of ACTH and Cortisol}

Baseline plasma measures (taken as the mean of the active and placebo 60-minute baselines) of ACTH (depression $6.4 \pm 2.7 \mathrm{pg} / \mathrm{ml}$; OCD $6.3 \pm 0.7 \mathrm{pg} / \mathrm{ml}$; healthy controls $4.8 \pm 0.7 \mathrm{pg} / \mathrm{ml}$;S) and cortisol (depression $5.4 \pm 0.9 \mu \mathrm{g} / \mathrm{dl}$; OCD $5.5 \pm 0.7 \mu \mathrm{g} / \mathrm{dl}$; healthy controls $4.3 \pm 0.6 \mu \mathrm{g} / \mathrm{dl} ; \mathrm{NS}$ ) were similar among all groups. 24hour excretion of UFC was significantly greater in depressed patients compared to healthy controls (depression $83.4 \pm 7.8 \mu \mathrm{g} / 24$ hours, healthy controls $62.3 \pm 5.9$ $\mu \mathrm{g} / 24$ hours; $p=.03$ ). Among depressed patients, seven of 15 had 24-hour UFC excretion above the upper limit of normal for this value (i.e., greater than $90 \mu \mathrm{g}$ cortisol/24 hours). There was no correlation between 24-hour excretion of UFC and Hamilton depression rating scores in depressed patients.

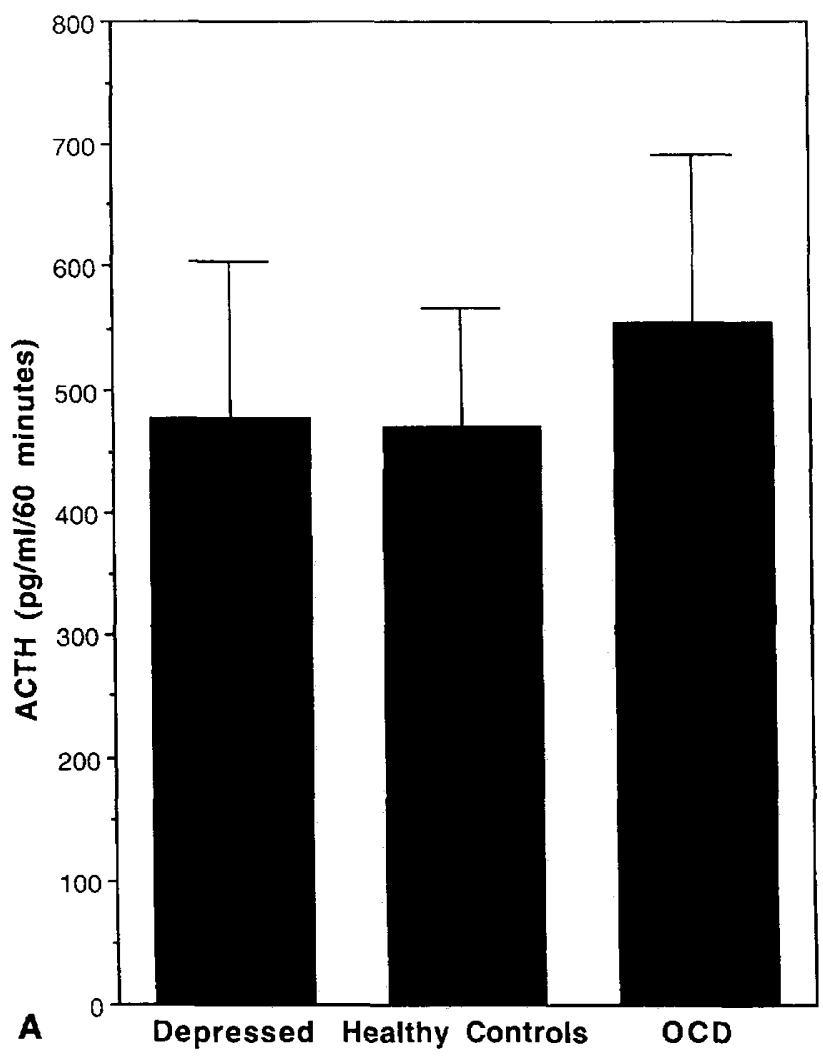

\section{Plasma ACTH and Cortisol Responses to Naloxone}

Both the net integrated ACTH and cortisol responses to naloxone administration were significantly elevated compared to placebo in all groups (ACTH response: naloxone $496 \pm 66 \mathrm{pg} / \mathrm{ml} / 60$ minutes; placebo $35 \pm 10$ $\mathrm{pg} / \mathrm{ml} / 60$ minutes; $p<.0001$; cortisol response: naloxone $321 \pm 37 \mu \mathrm{g} / \mathrm{dl} / 60$ minutes; placebo $20 \pm 8 \mu \mathrm{g} / \mathrm{dl} /$ 60 minutes; $p<.0001$ ). There was no significant difference among diagnostic groups in either the ACTH or cortisol response to naloxone. These results are summarized in Figures 1 and 2. Reanalysis of the data excluding those OCD patients with concurrent major depression showed no significant differences among groups. There was no correlation between 24-hour UFC excretion in depressed patients and either net integrated ACTH or cortisol responses to naloxone, nor were ACTH and cortisol responses correlated with baseline cortisol values.

\section{DISCUSSION}

The results of the current study do not show any difference in naloxone-induced activation of the HPA axis among patients with depression, OCD, and healthy controls, despite the fact that compared to controls the depressed patients studied did, as a group, show evi-

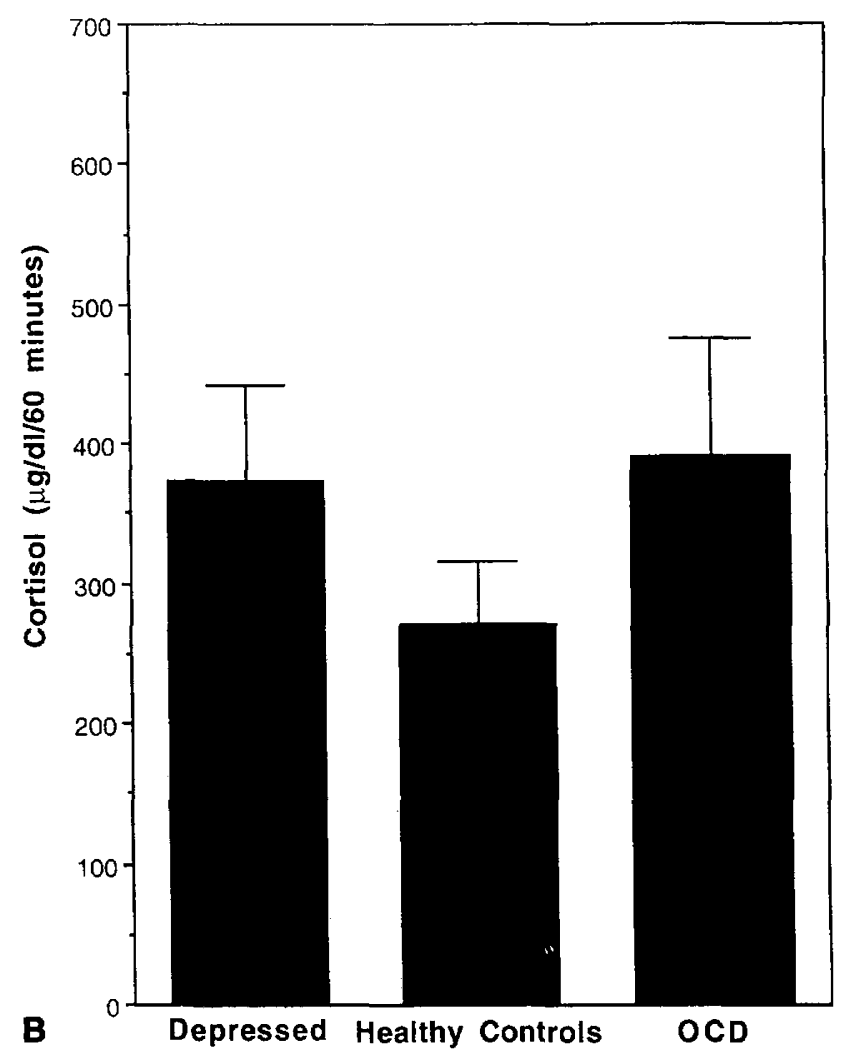

Figure 1. Net integrated $\mathrm{ACTH}(\mathrm{A})$ and cortisol (B) responses to naloxone administration. 


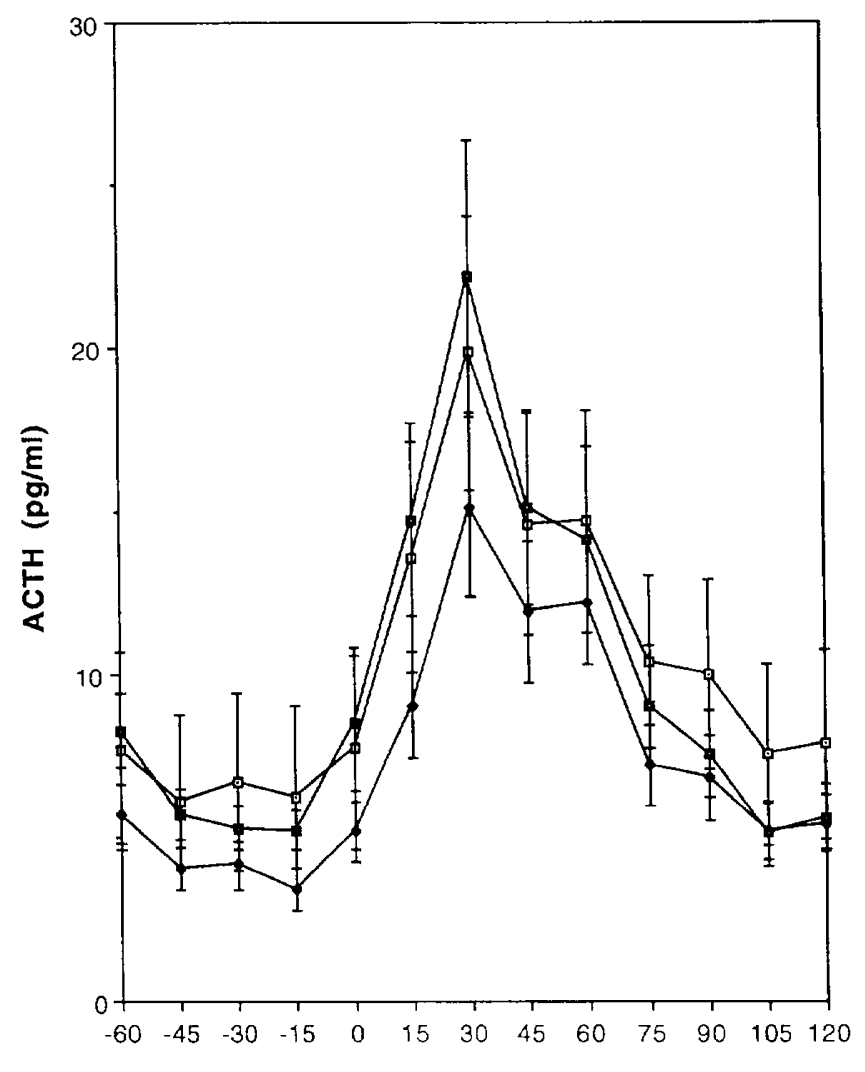

A

Time

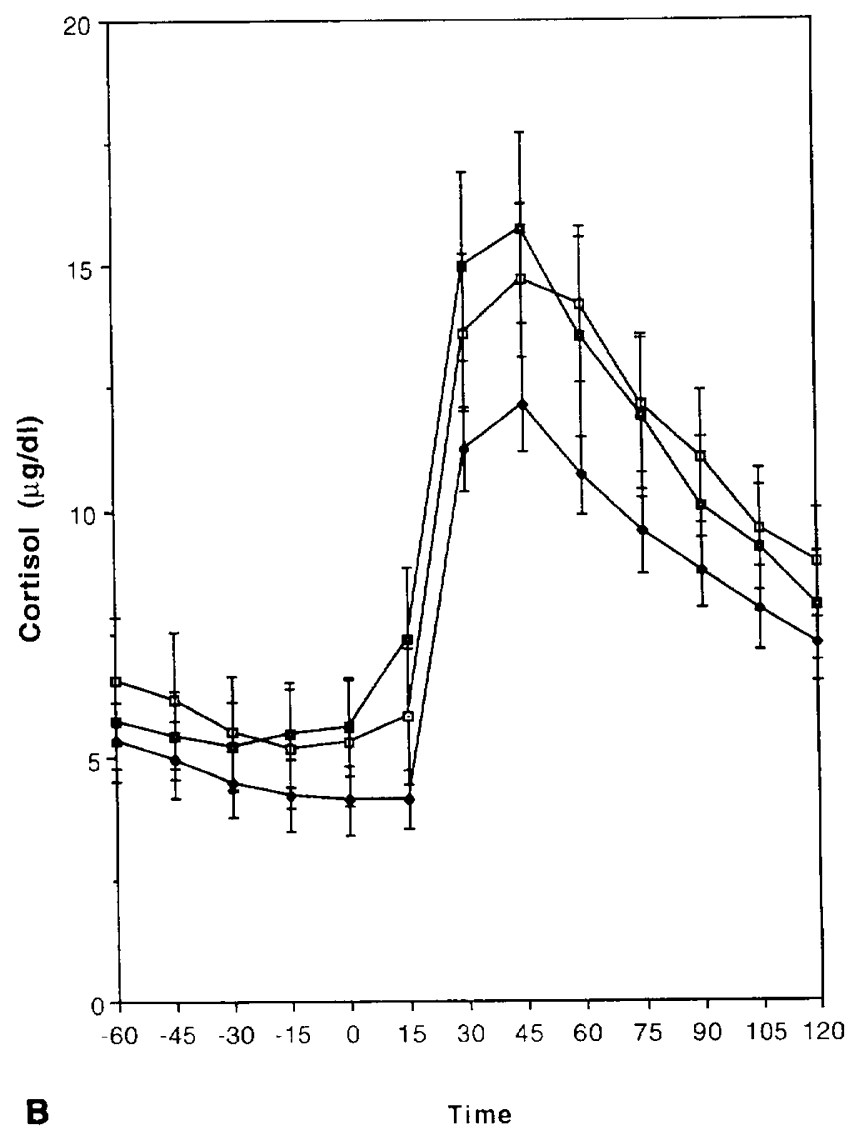

Figure 2. Time course of ACTH (A) and cortisol (B) responses to naloxone administration ( $\square$, depressed; $\bullet$, healthy control; $\mathbf{\square}, \mathrm{OCD})$.

dence of increased HPA axis activity as measured by 24hour UFC excretion (though not plasma cortisol levels). This similarity among groups, which is consistent with a previously reported study (Judd et al. 1981), may be accounted for by physiologic mechanisms related to HPA axis activity or may be related to methodologic issues. Although it could also be that no difference in response was observed because the locus of HPA axis dysregulation in depression is at the pituitary or adrenal gland, the weight of available evidence makes this explanation unlikely (Gold et al. 1986; Nemeroff et al. 1984).

It is possible that the lack of observed differences is related to the fact that the study was performed in the evening when the axis is normally quiescent. Because naloxone is thought to act by blocking tonic endogenous opiate inhibition of CRH secretion, it may be that an effect would be detectable at time when the HPA axis is more active (i.e., in the morning). It is also possible that differences among groups would have been observed examining larger numbers of subjects. We note, however, that the current data do not suggest even a trend toward statistically significant group differences and are consistent with the previously reported study (Judd et al. 1981). Heterogeneity of the depressed group in either underlying pathophysiology or variations in severity of depression could potentially also have masked differences among groups. Finally, it is possible that a different dose of naloxone would have uncovered differences between groups. One study reported that $6 \mu \mathrm{g} / \mathrm{kg}$ of naloxone detected group differences among normals and subjects with post traumatic stress disorder (PTSD) that were not seen with $125 \mu \mathrm{g} / \mathrm{kg}$ (Hockings et al. 1993). This study, however, had a number of methodologic problems including repeated administration of doses over several hours as well as a subject population on medications known to affect the HPA axis. In the dose-finding phase of the current study, the ACTH and cortisol responses to administration of naloxone at $25 \mu \mathrm{g} / \mathrm{kg}$ did not differ from the responses to placebo, and there was no increased response at doses above $175 \mu \mathrm{g} / \mathrm{kg}$. Further, other studies have reported ACTH and cortisol responses to naloxone of similar magnitude at comparable doses to the one used here, but not at very low doses (Delitala et al. 1994; Grossman et al. 1986).

Naloxone-induced pituitary-adrenal activation is probably a measure of both opiate tone and of hypothalamic CRH secretory activity. The findings of the current study suggest that opiate inhibitory tone over the 
hypothalamic CRH neuron is similar among all three groups studied. This is in itself of some interest, as it has been suggested that the pathophysiology of depressive illness could result from alterations in the endogenous opiate systems (Berger et al. 1986; Pickar et al. 1982). Other neurotransmitters thought to be associated with altered tone in depressive pathophysiology including serotonergic, noradrenergic, and cholinergic systems have also been shown to modulate CRH release by the hypothalamus (Calogero et al. 1988a, b, 1989). Unlike the current study with naloxone, however, in clinical studies each of these systems has been shown to have differential effects on pituitary-adrenal activation in comparisons of patients with depression and controls (Risch et al. 1983; Price et al. 1986; Maes et al. 1985).

Several other factors could explain the similarity of the ACTH and cortisol responses to naloxone despite apparent differences in HPA axis activity. The normal physiology of hypothalamic CRH secretion in humans is incompletely understood but is thought to involve pulsatile $\mathrm{CRH}$ release, probably superimposed on steady, low-level secretion. HPA axis hyperactivity in depression could be mediated by increased steady-state activity, increased frequency of $\mathrm{CRH}$ pulses, increased amplitude of CRH pulses, or some combination of these. It is also possible that some other factor such as increased AVP secretion is primarily responsible. We have recently compared the responses to exogenous argenine vasopressin (AVP) administration as well as exogenous CRH administration in multiple sclerosis (MS) and depression. The pattern of HPA axis activation in MS is consistent with increased AVP secretion (Michelson et al. 1994), whereas the pattern in depression differs from that of MS and is more consistent with increased $\mathrm{CRH}$ secretion (D. Michelson, unpublished data). However if AVP or some other factor were responsible for HPA activation in depression, it could account for the failure to observe differences among groups in this study. Finally, one recent study suggested that naloxone activates the pituitary-adrenal system through a nonCRH mechanism (Delitala et al. 1994), and though the evidence provided is preliminary, this could also explain the failure to observe differences.

Because naloxone blocks tonic endogenous opiate inhibition, it would be expected to increase $\mathrm{CRH}$ secretion rates and possibly to increase pulse amplitude; pulse frequency would seem less likely to be affected unless there is an undetectable flow of signals to the CRH neuron below a critical threshold that endogenous opiates normally mask. Because the axis is normally quiescent in the early evening hours during which this study was performed (i.e., little pulsatile activity is normally observed), it is likely that the increased activity induced by naloxone reflects a baseline level of secretion and suggests that HPA axis hyperactivity in depression may be related to either increased frequency or amplitude of pulsatile CRH secretion. It is also possible that the apparently "normal" ACTH and cortisol responses to naloxone in the depressed subjects are in fact inappropriately elevated. The elevations in 24-hour UFC excretion in the depressed patients as a group suggest an environment of HPA axis hyperactivity in which glucocorticoid negative feedback would be expected to dampen pituitary responsiveness. The observed response could represent a balance between increased hypothalamic CRH secretion and decreased pituitary responsivity.

In summary, naloxone induced pituitary-adrenal activation is not different from that of healthy of psychiatric controls, and abnormalities of the endogenous opiate systems do not appear to be involved in the pathophysiology of HPA axis activation in depression. Whereas naloxone is an effective central stimulus to pituitary-adrenal activation, it does not appear to be a useful tool for demonstrating central dysregulation of $\mathrm{CRH}$ secretion in depressed patients with hyperactivity of the HPA axis.

\section{REFERENCES}

Altemus M, Piggot T, Kalogeras KT, Demitrak MA, Dubbert B, Murphy DL, Gold PW (1992): Abnormalities in the regulation of vasopressin and corticotropin releasing factor secretion in obsessive compulsive disorder. Arch Gen Psychiatry 49:9-20

Berger PA, Watson SJ, Akil H, Barchas JD (1986): Investigating opioid peptides in schizophrenia and depression. In Martin JB, Barchas JD (eds), Neuropeptides in Neurologic and Psychiatric Disease. New York, Raven Press, pp 309-333

Calogero AE, Bernardini R, Margioris AN, Bagdy G, Gallucci W, Munson P, Tamarkin L, Tomai T, Brady L, Gold P (1989): Effects of serotonergic agonists and antagonists on corticotropin releasing hormone secretion by explanted rat hypothalami. Peptides 10:189-200

Calogero AE, Gallucci WT, Bernardini R, Saoutis C, Gold PW, Chrousos GP (1988a): Effect of cholinergic agonists and antagonists on rat hypothalamic corticotropin releasing hormone secretion in vitro. Neuroendocrinology 47:303-308

Calogero AE, Gallucci WT, Chrousos GP, Gold PW (1988b): Catecholamine effects upon rat hypothalamic corticotropin-releasing hormone secretion in vitro. J Clin Invest 82:839-846

Delitala G, Trainer PJ, Oliva O, Grossman AB (1994): Opioid peptide and alpha-adrenoceptor pathways in the regulation of the pituitary-adrenal axis in man. J Endocrinol $141: 163-168$

Gold PW, Loriaux DL, Roy A, Kling MA, Calabrese JR, Kellner $\mathrm{CH}$, Nieman LK, Post RM, Pickar D, Gallucci WT, Averginos PL, Paul SM, Oldfield EH, Cutler GB, Chrousos GP (1986): Responses to corticotropin-releasing hormone in the hypercortisolism of depression and Cushing's disease: Pathophysiologic and diagnostic implications. N Engl J Med 314:1329-1335 
Grossman A, Moult PJ, Cunnah D, Besser M (1986): Different opioid mechanisms are involved in the modulation of ACTH and gonadotropin release in man. Neuroendocrinology 42:357-360

Hockings GI, Grice JE, Ward WK, Walters MM, Jensen GR, Jackson RV (1993): Hypersensitivity of the hypothalamic-pituitary-adrenal axis to naloxone in post-traumatic stress disorder. Biol Psychiatry 33:585-593

Judd LL, Janowsky DS, Zittner A, Huey LY, Takahashi KI (1981): Effects of naloxone HCL on cortisol levels in patients with affective disorders and controls. Psychiatry Res 4:277-283

Maes M, Meltzer HY, D'Hondt P, Cosyns P, Blockx P (1995): Effects of serotonin precursors on the negative feedback effects of glucocorticoids on hypothalamic-pituitaryadrenal function in depression. Psychoneuroendocrinology 20:149-167

Michelson D, Stone L, Galliven E, Magiakou M, Chrousos GP, Sternberg E, Gold PW (1994): Multiple sclerosis is associated with alterations in hypothalamic pituitary adrenal axis function. J Clin Endocrinol Metab 79:848853

Morley JE, Baranetsky NG, Wingert TD, Carlson HE, Hershman JM, Melmed S, Levin SR, Jamison KR, Weitzman R, Chang RJ, Yarner AA (1980): Endocrine effects of naloxone-induced opiate receptor blockade. J Clin Endocrinol Metab 50:251-257
Nemeroff CB, Wilderov E, Besette G, Walleus H, Karlsson I, Eklund K, Kilts CD, Loosen PT, Vale W (1984): Elevated concentrations of CSF corticotropin-releasing factor-like immunoreactivity in depressed patients. Science 226: 1342-1344

Nikolarakis K, Pfeiffer A, Stalla GK, Herz A (1987): The role of $\mathrm{CRH}$ in the release of ACTH secretion by opiate agonists and antagonists in rats. Brain Res 421:373-376

Pickar D, Extein I, Gold PW, Summers R, Naber D, Goodwin FK (1982): Endorphins and affective illness. In Shah NS, Donald AG (eds), Endorphins and Opiate Antagonists in Psychiatric Research: Clinical Implications. New York, Plenum, pp 375-397

Price LH, Charney DS, Rubin AL, Heninger GR (1986): Alpha 2-adrenergic receptor function in depression. The cortisol response to yohimbine. Arch Gen Psychiatry 43:849-858

Risch JC, Janowsky DS, Gillin JC (1983): Muscarinic supersensitivity of anterior pituitary ACTH and $\beta$-endorphin release in major depressive illness. Peptides 4:789-792

Rittmaster R, Cutler G, Sobel D, Goldstein D, Kopelman M, Loriaux DL, Chrousos GP (1985): Morphine inhibits the pituitary-adrenal response to ovine corticotropin releasing hormone in normal subjects. J Clin Endocrinol Metab 60:891-895

Volavka J, Cho D, Mallya A, Bauman J (1979): Naloxone increases $\mathrm{ACTH}$ and cortisol levels in man. $\mathrm{N}$ Engl J Med 300:1056-1057 